\title{
PENGARUH PENAMBAHAN NIKEL TERHADAP KEKUATAN TARIK DAN KEKERASAN PADA BESI TUANG NODULAR 50
}

\author{
Sudarmanto \\ Prodi Teknik Mesin \\ Sekolah Tinggi Teknologi Adisutjipto \\ Jalan Janti Blok R Lanud Adisutjipto, Yogyakarta
}

\begin{abstract}
Nodular cast iron is the cast iron that has nodular graphite spherical structure distributed in ferrite or pearlite matrix or in both of them. Recently, this material is used widely in industries because its low cost and better performance. The advanced metal industries nowadays have found some new technologies in order to improve the properties of materials. One of them is the addition of another elements into the base metals, such as nickel. The effects of the addition $1 w t \%, 2 w t \%$ and $3 w t \%$ nickel into nodular cast iron 50 on tensile and hardness properties were investigated in this study. The experimental results show that the best amount of nickel that added into nodular cast iron is $3 \% w t$, which has the best tensile and hardness properties.
\end{abstract}

Keywords : nodular cast iron, nickel, tensile, hardness

\section{Pendahuluan}

Tujuan dari proses manufaktur metalurgi adalah untuk menghasilkan produk yang dapat berfungsi sesuai dengan spesifikasinya, dapat diterima oleh konsumen dan mempunyai nilai ekonomis, baik untuk produsen maupun konsumen. Untuk mencapai sasaran ini penting sekali memprediksi sifat-sifat mekanik, dalam hal ini kekuatan tarik dan kekerasannya. Oleh karena itu dalam pemilihan material dalam manufaktur harus mempertimbangkan sifat-sifat mekanis tersebut.

Pada penelitian ini material besi tuang nodular digunakan karena memiliki beberapa keunggulan yaitu mudah dan murah biaya produksinya dibandingkan dengan baja karbon. Proses produksinya cukup sederhana, mudah pemesinannya, tahan terhadap daya tekan, tahan aus dan tahan korosi yang lebih baik dari pada baja. Besi tuang nodular yang dipakai adalah besi tuang nodular 50 (BTN-50) tanpa proses ADI, yaitu dengan menambah unsur paduan $1 \%, 2 \%$ dan 3\% Nikel. Penelitian ini diharapkan dapat memberikan masukan untuk mendapatkan solusi untuk mengatasi permasalahan tersebut.

Besi tuang nodular sejak ditemukan pada tahun 1948, sampai sekarang ini merupakan material yang banyak digunakan pada pembuatan komponen-komponen otomotif. Besi tuang nodular banyak digunakan karena memiliki beberapa keunggulan yaitu mudah dan murah biaya produksinya dibandingkan dengan baja karbon. Bentuk grafit yang bulat ini diakibatkan adanya unsur pembuat grafit yang disebut noduliser. Pembuatan besi tuang nodular biasanya dengan menggunakan sistim ladle yang sering digunakan adalah ladle sandwich, tudish, teapot tudish dan double teapot. Akibat bentuk grafit yang bulat ini, maka kekuatan tarik material dalam kondisi ascast meningkat dibandingkan bentuk grafit serpihan dari nilai $10-30$ $\mathrm{Kg} / \mathrm{mm} 2$ sehingga menjadi $60 \mathrm{Kg} / \mathrm{mm} 2$, sementara regangannya biasa mencapai $12 \%$. Dengan pesatnya penggunaan besi tuang nodular ini, telah banyak dilakukan usaha untuk meningkatkan sifat mekanisnya. Sifat mekanis besi tuang nodular terutama sangat dipengaruhi oleh struktur mikronya. Perubahan struktur mikro dapat dilakukan dengan proses perlakuan panas atau dengan proses pemaduan. 
Keistimewaan dari besi tuang nodular ini adalah mempunyai sifat lebih baik, terutama sifat mekaniknya dibanding dengan besi tuang lainnya. Sifat mekanik besi tuang nodular adalah mempunyai kekuatan tarik yang tinggi, mampu mesin yang baik, tahan aus dan jika ditambah unsur paduan dapat dipergunakan tanpa perlakuan panas. Material ini biasa digunakan untuk alat-alat mobil, mesin pertanian, poros engkol, roda gigi dan lain sebagainya.

Pengaruh kandungan Ni pada besi tuang nodular adalah penambahan Ni pada ascast, sebagian terjadi matrik ferrit, selama pembentukan pearlite atau acicular sampai $4 \%$, kualitas austenitic dari $18 \%$ sampai $36 \%$ yang kualitasnya baik. Nikel biasanya ditambahkan dengan Mg sebagai logam paduan pengikat. Secara signifikan persentase kandungan Ni paling besar seperti Nikel Magnesium Alloy dan selanjutnya sebagi paduan (Nikel, Magnesium, Silisium Alloy) merupakan paduan logam utama.

Nikel memperkuat ferrit dan berperan untuk mengurangi karbida kotor seperti sebagai pembentukan grafit dengan lebih kurang 50\% dari keefektifan Si. Dengan penambahan Nikel $1 \%$ akan meningkatkan kekuatan tarik dan luluh sekitar 5000 Psi, dengan penurunan elongation sekitar $1-2 \%$. Dengan kenaikan $3 \%$ Nikel akan meningkatkan kekuatan tarik sekitar 120.000 Psi dengan elongation $3 \%$, pada besi tuang nodular akan terbentuk matrik ferrit dengan pendinginan lambat, sehingga kekuatan tarik dan kekerasan meningkat. Nikel padat mengakibatkan kemampuan tuang tinggi dalam berbagai nilai konsentrasi paduan maksimum yang ditentukan.

\section{Metodologi Penelitian}

\subsection{Bahan dan Alat}

Bahan yang digunakan adalah besi tuang nodular 50, Nikel, pasir cetak, pola Y blok dari kayu dengan standar JIS G 5503 No. B dan alat pembuatan cetakan, sebelum logam cair dituangkan kedalam cetakan ditambahkan Nikel dengan persentase berat $1 \%, 2 \%$ dan $3 \%$. Adapun alat yang digunakan dalam penelitian ini adalah alat uji tarik, alat uji kekerasan, dan jangka sorong.
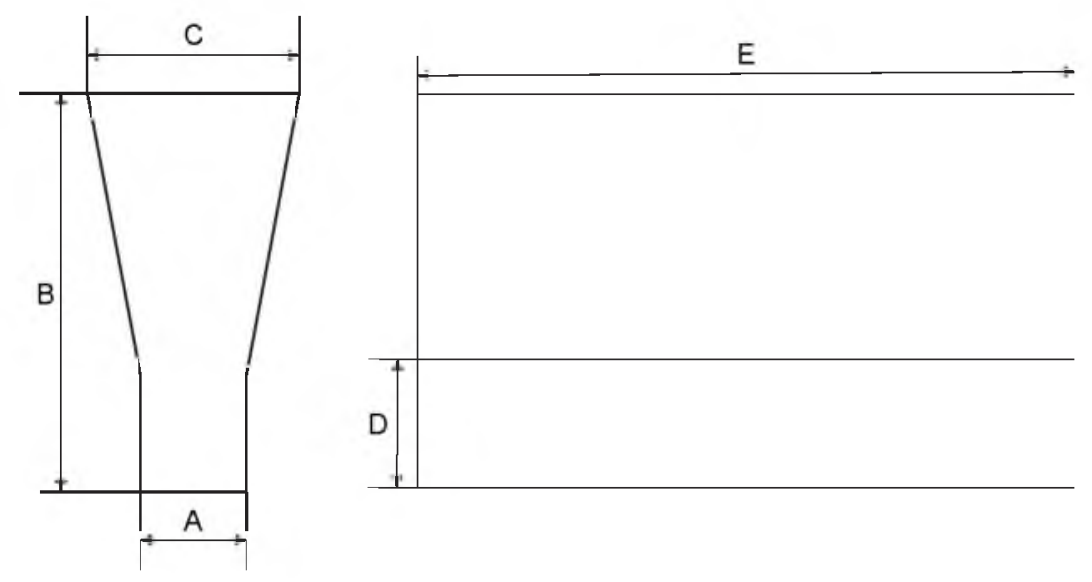

Gambar 1. Y Blok standar JIS G 5503 No. B 
Tabel 1. Ukuran Y Blok

Ukuran Y Blok (mm)

\begin{tabular}{cccccc}
\hline Jenis & A & B & C & D & E \\
\hline No. a & 12 & 135 & 25 & 40 & $150 \mathrm{~min}$ \\
\hline No. b & 25 & 140 & 40 & 55 & $150 \mathrm{~min}$ \\
\hline
\end{tabular}

\subsection{Pengujian Spesimen}

Pengujian tarik pada penelitian ini mengacu pada standar JIS G 5503 No. B, dan pengujian kekerasan menggunakan Rockwell Hardness Test.

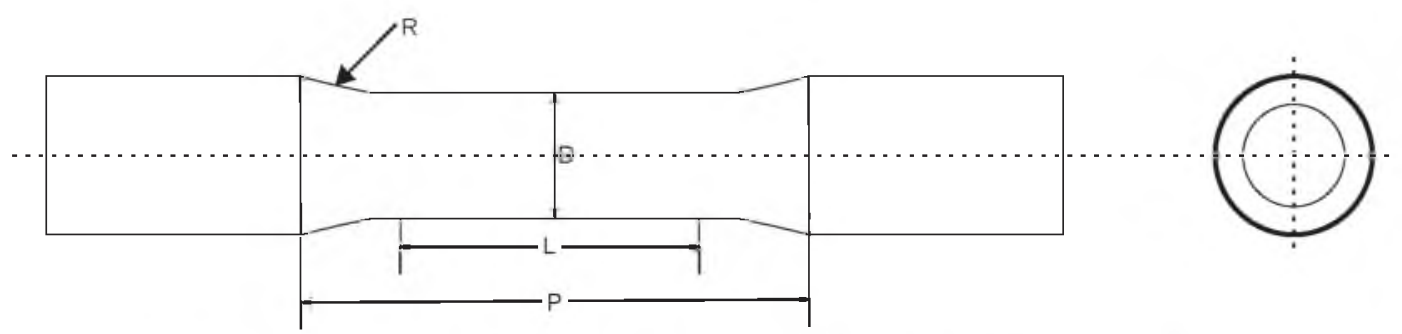

Gambar 2. Standar spesimen uji tarik menurut standar JIS G. 5503 No. B

Tabel 2. Dimensi spesimen uji tarik menurut standar JIS G. 5503 No. B

\begin{tabular}{lll}
\hline Gauge length & $\mathrm{L}$ & 50 \\
\hline Diameter & $\mathrm{D}$ & 14 \\
\hline Radius of fillet & $\mathrm{R}$ & $15 \mathrm{Min}$ \\
\hline Length of reduced & $\mathrm{P}$ & 50 approx \\
\hline
\end{tabular}

\section{Hasil dan Pembahasan}

\subsection{Pengujian Komposisi Kimia}

Pengujian ini dilakukan untuk mengetahui unsur - unsur paduan yang terkandung pada sampel uji. Sampel yang diuji adalah : as-cast, as-cast $+1 \% \mathrm{Ni}$, as-cast $+2 \% \mathrm{Ni}$ dan as-cast + $3 \%$ Ni. Pengujian komposisi ini dilakukan di laboratorium metalurgi UI Jakarta, adapun hasilnya adalah seperti pada tabel 3 .

\subsection{Pengujian Mekanik}

Pengujian sifat mekanis dilakukan pada BTN-50 as-cast maupun pada variasi komposisi paduan $1 \%, 2 \%$ dan $3 \%$ Nikel yang meliputi pungujian kekuatan tarik dan pengujian kekerasan.

\section{A. Pengujian Kekuatan Tarik}

Dari grafik pengaruh penambahan Ni pada As-cast terhadap kekuatan tarik (Gambar 3) dapat dilihat bahwa dengan penambahan paduan $1 \%, 2 \%$ dan $3 \% \mathrm{Ni}$ pada tuangan $\mathrm{BTN}-50$ standar blok JIS G 5503 No. B kekuatan tarik tertinggi di dapat pada penambahan paduan 3\% $\mathrm{Ni}$, yaitu sebesar $78 \mathrm{~kg} / \mathrm{mm}^{2}$. Terdapat kenaikan sebesar $27 \mathrm{~kg} / \mathrm{mm}^{2}$ atau sebesar $34,6 \%$ bila dibandingkan dengan kondisi as-cast yaitu sebesar $51 \mathrm{~kg} / \mathrm{mm}^{2}$. Kenaikan kekuatan tarik tersebut adalah signifikan. Dapat dilihat pula bahwa kenaikan penambahan nikel sebanding dengan kenaikan kekuatan tariknya. 
Tabel 3. Data hasil uji komposisi kimia

\begin{tabular}{|c|c|c|c|c|}
\hline \multirow{2}{*}{ Unsur Kimia } & \multicolumn{4}{|c|}{ Kandungan pada sampel uji (\%) } \\
\cline { 2 - 5 } & \multirow{2}{*}{ As-Cast } & $\begin{array}{c}\text { As-Cast }+ \\
1 \% \mathrm{Ni}\end{array}$ & $\begin{array}{c}\text { As-Cast + } \% \\
\mathrm{Ni}\end{array}$ & $\begin{array}{c}\text { As-Cast + 3\% } \\
\mathrm{Ni}\end{array}$ \\
\hline $\mathrm{C}$ & 3,50 & 3,50 & 3,59 & 3,05 \\
$\mathrm{Si}$ & 2,96 & 2,97 & 2,93 & 2,79 \\
$\mathrm{Mn}$ & 0,05 & 0,05 & 0,04 & 0,02 \\
$\mathrm{P}$ & 0,02 & 0,02 & 0,017 & 0,019 \\
$\mathrm{~S}$ & 0,01 & 0,012 & 0,01 & 0,015 \\
$\mathrm{Ni}$ & 0,04 & 1,10 & 2,45 & 3,55 \\
$\mathrm{Cr}$ & 0,03 & 0,03 & 0,03 & 0,003 \\
$\mathrm{Mo}$ & 0,004 & 0,006 & 0,005 & 0,005 \\
$\mathrm{Cu}$ & 0,39 & 0,41 & 0,41 & 0,42 \\
$\mathrm{~V}$ & 0,007 & 0,007 & 0,007 & 0,008 \\
$\mathrm{Ti}$ & 0,01 & 0,01 & 0,01 & 0,01 \\
$\mathrm{Al}$ & 0,02 & 0,02 & 0,02 & 0,01 \\
$\mathrm{Sn}$ & 0,009 & 0,01 & 0,009 & 0,009 \\
$\mathrm{~Pb}$ & 0,009 & 0,011 & 0,009 & 0,009 \\
$\mathrm{Mg}$ & 0,04 & 0,03 & 0,033 & 0,034 \\
$\mathrm{Fe}$ & $\mathrm{Rem}$. & Rem. & Rem. & Rem. \\
\hline
\end{tabular}

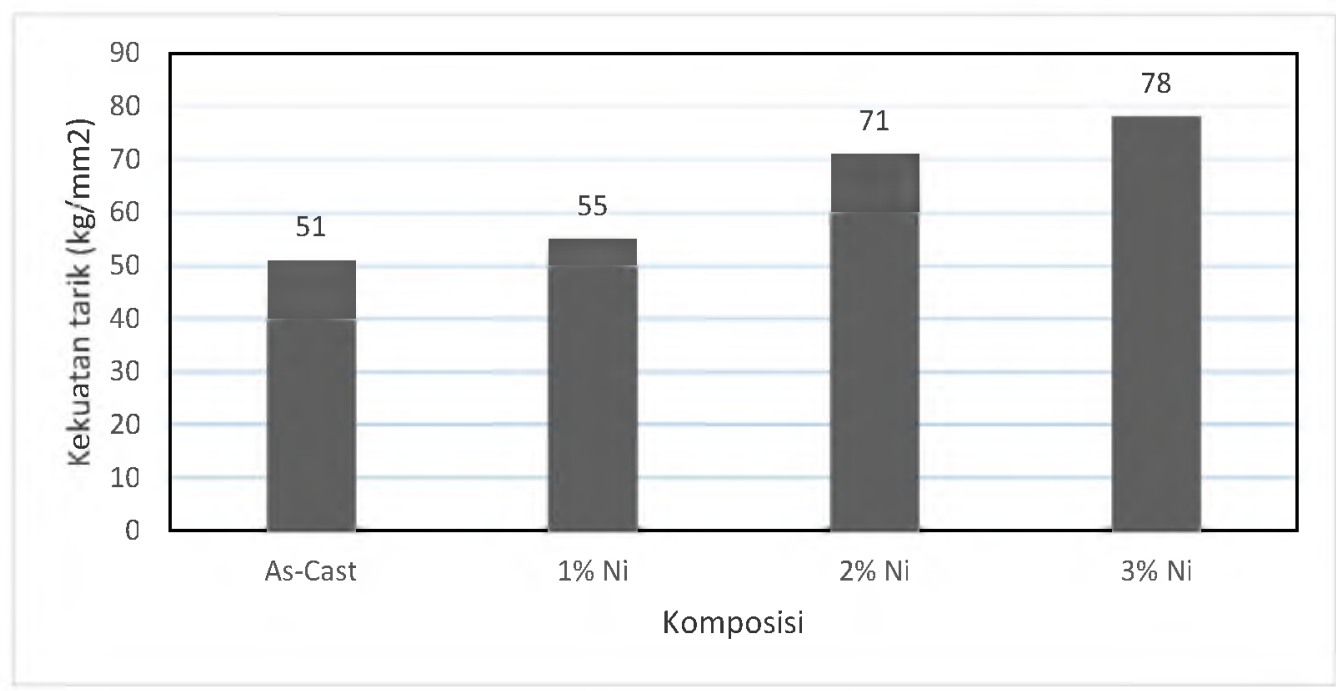

Gambar 3. Pengaruh penambahan Ni pada As-cast terhadap kekuatan tarik.

Dari grafik pengaruh penambahan Ni pada As-cast terhadap elongasi (Gambar 4) dapat dilihat bahwa dengan penambahan unsur paduan $1 \%, 2 \%$ dan $3 \%$ Ni pada as-cast BTN 50 elongasi tertinggi diperoleh pada penambahan paduan $3 \%$ Ni sebesar $5,08 \%$, sehingga terjadi kenaikan sebesar 14\% bila dibandingkan dengan kondisi as-cast di mana elogansinya sebesar $4,35 \%$. Penambahan unsur nikel ini dapat meningkatkan elongasi, di mana semakin banyak penambahan nikel maka semakin besar pula elongasinya. 


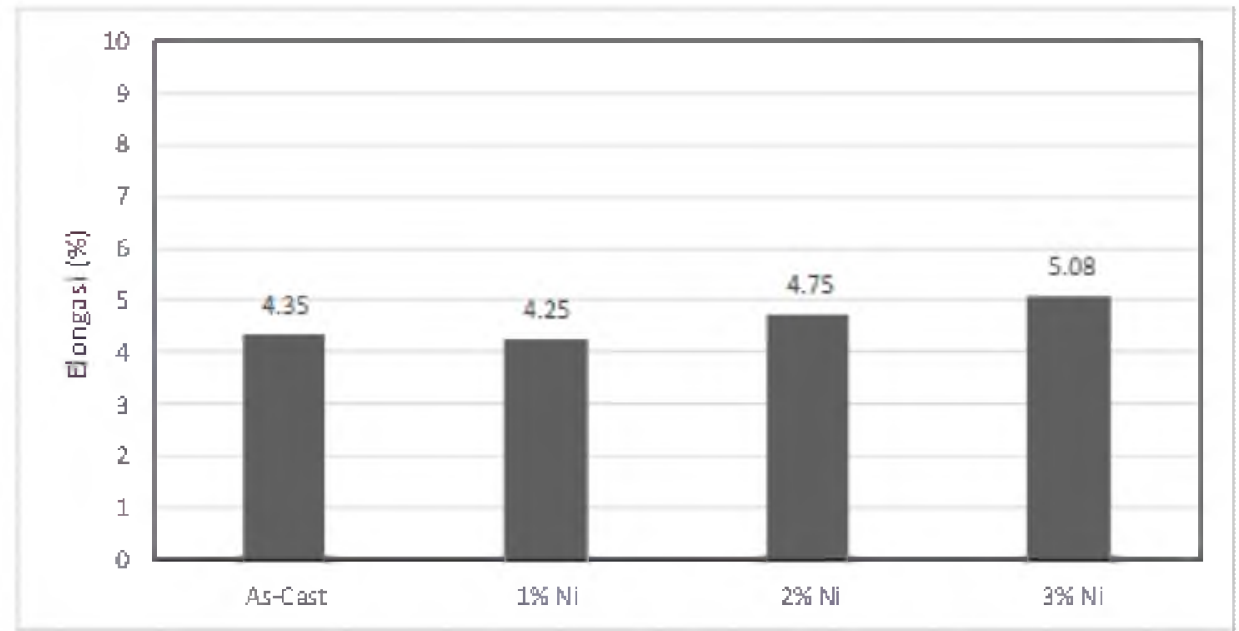

Gambar 4. Pengaruh penambahan Ni pada As-cast terhadap elongasi.

\section{B. Pengujian kekerasan}

Pada grafik pengaruh penambahan Nikel terhadap kekerasan (Gambar 5) dapat dilihat bahwa dengan penambahan paduan Nikel 1\%, 2\% dan 3\% pada BTN-50 maka terdapat kenaikan nilai kekerasan di mana kekerasan yang tertinggi didapat pada penambahan paduan Nikel 3\% yaitu sebesar 335 BHN jadi ada kenaikan sebesar 35,6\% jika dibandingkan dengan kondisi as-cast di mana harga kekerasannya adalah $247 \mathrm{BHN}$.

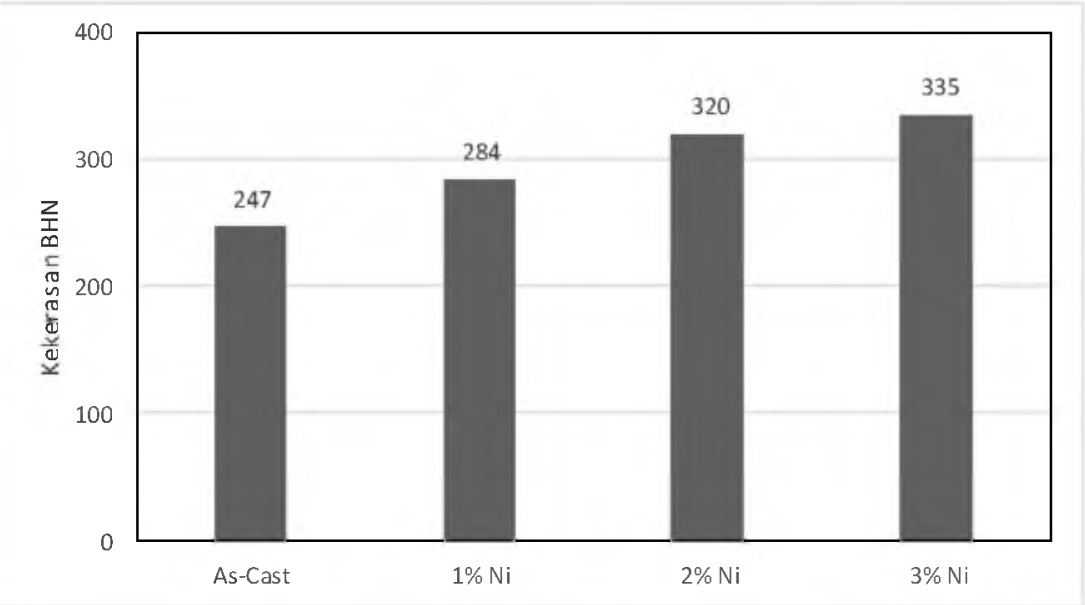

Gambar 5. Grafik pengaruh penambahan Nikel terhadap kekerasan

\section{Kesimpulan}

Dari variasi penambahan unsur paduan $1 \%, 2 \%$ dan $3 \%$ Nikel pada besi tuang nodular 50 dapat disimpulkan bahwa semakin besar unsur Nikel yang ditambahkan pada besi tuang nodular 50 maka semakin besar kekuatan tarik, elongasi, dan kekerasannya. Penambahan $1 \%$ $\mathrm{Ni}$ pada As-cast diperoleh kekuatan tarik $55 \mathrm{~kg} / \mathrm{mm}^{2}$, elongasi 4,25\% dan kekerasan 105 $\mathrm{HRB}$, penambahan $2 \% \mathrm{Ni}$ pada As - cast diperoleh kekuatan tarik $71 \mathrm{~kg} / \mathrm{mm}^{2}$, elongasi 4,75\% dan kekerasan $107 \mathrm{HRB}$, penambahan 3\% Ni pada As - cast diperoleh kekuatan tarik $78 \mathrm{~kg} / \mathrm{mm}^{2}$, elongasi 5,08\% dan kekerasan $109 \mathrm{HRB}$. Kekuatan tarik, elongasi dan kekerasan tertinggi diperoleh pada paduan $3 \%$ Ni yaitu $78 \mathrm{~kg} / \mathrm{mm}^{2}, 5,08 \%$ dan $109 \mathrm{HRB}$. 
Sudarmanto

\section{Daftar Pustaka}

Bustanul, A, 1999, Peningkatan Kinerja Poros Engkol BTN - Normalisasi Dengan Proses Pemaduan Tembaga 0,33\%, Jurnal Teknologi, vol. 3 .

Skalan, T, Elkem, ASA, 1999, Ductile Iron Production - A Comparison of Altrnative Treatment Method, Metal Asia.

Spengler, AF, 1985, The Ductile Iron Press, Compendium, VII, Miller and Company, Chicago.

Surdia, T, Chjiwa, K, Teknik Pengecoran Logam, P.T. Pradnya Paramita, Jakarta.

ASM, 1982, Metal Handbook, Ferrous, Vol. 2, $9^{\text {th }}$ Edition Metals, Park, Ohio.

JIS, 1999, Handbook, Ferrous, Material and Metallurgy. 